\title{
La Marcha de las PuTAS: SEXUALIDAd, CONTROL Y RESISTENCIAS
}

\section{Slutwalk: sexuality, control and resistances}

\author{
Jessica Tatiana Castaño Urdinola \\ jessica.castano@ucaldas.edu.co \\ Universidad de Caldas - Colombia
}

\author{
Milton Andrés Salazar \\ andres.salazar@ucaldas.edu.co \\ Universidad de Caldas - Colombia
}

Recibido: 19-01-2017

Aceptado: 03-06-2017

\section{Resumen}

La construcción discursiva de las mujeres como "brujas" o "putas" ha sido una de las tantas formas en que históricamente se les han oprimido y controlado sexopolíticamente. Este artículo tiene como objetivo evidenciar cómo la "La Marcha de las Putas" en Manizales ha sido una insolente, creativa y experimental práctica colectiva de resistencia que cumple, a partir de la transgresión, el papel de desentrañar las violencias ejercidas por el patriarcado a través de sus perversas categorizaciones. La Puta como locus de lucha de política es entonces una estratégica, paródica y postidentitaria categoría de resistencia.

Palabras Clave: Resistencias, Puta, violencia de género, transgresión.

\begin{abstract}
The discursive construction of women as "witches" or "sluts" has been one of the many ways that they have historically been sex-politically oppressed and controlled. This article has as objective to show how the Slutwalk in Manizales has been configured as a creative and experimental collective practice of resistance. From transgression, it fulfills the role of unraveling the patriarchy violence through their perverse categorizations upon women. Therefore, the slut as locus of political struggle will be a strategic, parodic and post-identitary resistance category.
\end{abstract}

Keywords: Resistances, Slut, gender-based Violence, transgression. 
Nosotras las novias, las quitamaridos, las mostronas, las madres con hijos de padres diferentes, las trabajadoras sexuales, las que sacan a bailar, las estudiantes, las marihuaneras, las que se masturban, las alegres, las amargadas y las hijas de puta, nos apropiamos del insulto PUTA para afirmar ante el mundo que inada justifica la violencia sexual!, que el espacio público es nuestro y podemos ocuparlo libremente. ¿Puta? PUTÍSIMA y cuando digo NO es NO (Manifiesto Marcha de las Putas Manizales, 2014).

\section{Introducción}

En este artículo, se aborda la práctica colectiva de resistencia transnacional llamada "Marcha de las Putas", que tiene expresión en Colombia en la ciudad de Manizales. En la primera parte, se reflexiona sobre dos categorías que han sido utilizadas históricamente para ejercer un control social y sexual sobre las mujeres: la bruja y la puta. Luego, se ofrecen algunos datos sobre violencia hacia las mujeres que señalan la indignación de mujeres y hombres que motiva insurgencias, disidencias y resistencias al imperio sexual. En el tercer y último momento, se analizan los colectivos de resistencia sexual de la ciudad, centrados en dos iniciativas: la Marcha de las Putas y los "Putalleres".

Considerando que el artículo es de reflexión, la información se sustenta en el trabajo realizado desde el 2013 por el colectivo de investigación Pluriversos, Cultura y Poder que realiza seguimiento a la acción colectiva de la ciudad. Datos obtenidos de una caracterización de colectivos sociales realizada en el 2015, junto con entrevistas semi-estructuradas a líderes de los colectivos indagados y ejercicios etnográficos de los eventos, además de la participación directa del colectivo de investigación en la planeación y acompañamiento de algunas de las actividades que aquí se describen y su respectiva sistematización configuran la estrategia metodológica desarrollada para la construcción de este artículo ${ }^{1}$.

\footnotetext{
${ }^{1}$ La caracterización de colectivos sociales fue realizada por el colectivo "Pluriversos, Cultura y Poder" en el 2015 a 28 colectivos de la ciudad de Manizales, entre ellos la mayoría de los mencionados en este artículo. Igualmente es preciso mencionar que algunos de los miembros del colectivo de investigación hemos participado directamente en el desarrollo de La marcha de las putas y de los putalleres, lo que nos convierte tanto en sujetos obejtivantes como objetivados. No obstante, siguiendo a Boaventura de Sousa Santos (2006) apelamos con rigor a la objetividad mas no a la neutralidad; reconociendo las contradicciones que emergen de estas luchas, sabemos de qué lado estamos.
} 


\section{De brujas a putas}

\subsection{Las mujeres como brujas}

En la Edad Media "los herejes" fueron una fuerza opositora a la consolidación del poder político, económico y social de la iglesia católica. Sin embargo, no eran simplemente sujetos aislados que tenían comportamientos pecaminosos o peligrosos, sino que, de acuerdo con Silvia Federici, fueron un movimiento consolidado que conscientemente intentaba transformar su sociedad: "Las principales sectas herejes tenían un programa social que reinterpretaba la tradición religiosa, y al mismo tiempo estaban bien organizadas desde el punto de vista de su sostenimiento, la difusión de sus ideas e incluso su autodefensa" (2010: 53).

La iglesia, liderada por el Papa Pablo III, en 1542, creó la Sagrada Congregación de la Romana y Universal Inquisición, dirigida especialmente a la represión de los herejes. Operaba persiguiéndolos y quemándolos en la hoguera en presencia de las multitudes, para advertir a la gente sobre las consecuencias de contradecir los dogmas de la Iglesia. Desde la temprana Edad Media, la iglesia persiguió las herejías, pero solo con la creación de la inquisición empezó a aplicar la pena de muerte a los herejes. Y, aunque nunca hubo una unificación de las herejías en algo como un movimiento que se opusiera al papa de Roma, la iglesia sintió en muchos momentos una especie de conspiración organizada en la que incluyó, hacia el siglo XIV, a las brujas (Ángel, n.d.). El hecho es que había muchas mujeres que comprendían que para la iglesia su comportamiento sexual debía ser regulado, y se les impuso el rótulo de pecadoras, portadoras de la tentación. Además, ellas habían creado estrategias para controlar sus cuerpos y su sexualidad como la anticoncepción y el aborto, que ya en ese entonces eran asociadas con prácticas demoníacas, de ahí que la Inquisición las llamara "brujas", un vocablo que no proviene del latín ni del griego sino, probablemente, de alguna lengua ibérica o del nórdico antiguo.

Algunos mecanismos de la iglesia para perseguir a estas mujeres, fueron difundidos a través la bula pontificia del Papa Juan XXII del año 1326, en la que se ordenaba expulsarlas de la misa y negarles los sacramentos y las emparentaba con el diablo. En esta forma, se origina un imaginario sobre la sexualidad no reproductiva como un asunto vergonzoso y pecaminoso, y hacía de quienes abortaran, se masturbaran, tuvieran prácticas sodomitas y controlaran la concepción, en agentes del demonio por obstaculizar la reproducción. Al difundirse el estigma sobre las brujas, crecen también las precauciones frente al tipo de mujeres que ingresaban a las viviendas, como las sirvientas, pues, al ser encargadas del cuidado de los niños, de la limpieza y la alimentación, se corría el riesgo de que asesinaran a los niños para ofrecérselos al demonio (lo que fue llevado más tarde a los cuentos infantiles) o usaran, en complicidad con las esposas, brebajes anticonceptivos o abortivos.

Así, entonces, en la Edad Media y a comienzos de la modernidad en occidente, el cuerpo de las mujeres, especialmente sus úteros, empezaron a ser territorializados y controlados políticamente por el poder religioso y jurídico, justificando sus actos con las prescripciones 
católicas sobre el sexo y la reproducción, lo que llevó a asesinar a miles de mujeres en Europa acusadas de brujería. Esta práctica llegó a América durante la colonización. Este control sexopolitico de las mujeres fue coherente con el nacimiento de una economía capitalista que necesitaba del crecimiento de una fuerza trabajo para las incipientes fábricas, y de todas las persecuciones que fueran necesarias a quienes lo obstaculizaran.

Pero entonces, ¿quiénes eran en realidad las brujas? Según Blazquez (2008), si bien, había mujeres que se dedicaban a realizar maleficios y causar la muerte, las brujas eran quienes conocían las diferencias entre distintas plantas, los espacios y tiempos en donde crecían, sus posibles usos y funciones, sus variedades y los métodos para su utilización. También construyeron sus propios instrumentos para experimentar, conservar y preparar sus productos que eran principalmente medicinales, gastronómicos y cosméticos. La consecución de los resultados se lograba con técnicas químicas como la destilación y la sublimación, que en ese entonces sólo eran reconocidas y exaltadas para los alquimistas.

Mientras que la visión dogmática de la iglesia católica hacia las mujeres les asignaba un lugar de inferioridad, pasividad e insignificancia, los herejes aparecen como una vía de escape ante ese modelo de feminidad, pues, como lo expresa GioacchinoVolpe (1971), muchos herejes consideraban a las mujeres como iguales a los hombres en lo referente a la vida social, al trabajo y a la movilidad. Pensaban incluso que podían bautizar y ser sacerdotisas, administrar los sacramentos que para los católicos era una potestad exclusivamente masculina.

Las brujas fueron mujeres desobedientes, ilustradas, curiosas, eróticas, independientes, indomables, lo que las convierte en villanas de la vida social y familiar, personaje que más tarde va a encarnar la "puta". Este tipo de feminidad va a ser confrontada y reprimida a través de una serie de regulaciones que fueron consolidando un nuevo estereotipo que ya no se refería a las mujeres como seres indómitos, como el caso de las brujas, sino como seres pasivos, asexuados y mejores moralmente, gracias a la intervención de los dispositivos jurídicos y religiosos.

¿Cuál fue el costo de la construcción de esta nueva feminidad? Según el estudio de Blazquez (2008), la literatura más confiable establece unas 110.000 acusaciones por brujería y 60.000 ejecuciones. De estas cifras, las procesadas fueron en un $75 \%$ mujeres en la mayoría de países europeos, aunque en algunas regiones superó el 90\%. Para otras autoras, estas cifras son inexactas, puesto que no están documentadas las muertes en prisión por hambre o tortura, los suicidios ni los linchamientos. Además, estos datos sólo corresponden al continente europeo, pues no incluye la cacería de brujas que se produjo en América a partir de la colonización, proceso que trasladó las creencias misóginas a estas poblaciones, donde las mujeres tenían roles muy distintos a los de las europeas.

A pesar de esta genocidio-epistemicidio, la emblemática frase feminista "Somos las nietas de las brujas que no pudiste quemar", que aparece constantemente en manifestaciones públicas y encuentros de distinta índole, indica la imposibilidad de forzar la desaparición de formas de ser mujer y saberes que se aíslan del prototipo dominante y que siguen germinando en distintas latitudes. 


\subsection{Las brujas de ayer son las putas de hoy}

En el presente siglo, las brujas son encarnadas por un nuevo sujeto que se reprime: la "puta". Hay dos acepciones para esta palabra: la primera tiene que ver con la definición que ofrece Sebastián Covarrubias (1611): “"puta” es una mujer ruin o ramera; proviene del latín putida que significa podrida o de mal olor, por su condición callejera”. Esta definición alude al posible nacimiento de la palabra (su origen es incierto) como sinónimo de prostituta, es decir, de una mujer que ofrece servicios sexuales en el espacio público a cambio de cierta cantidad de dinero. El segundo sentido que se le otorga está orientado hacia el modelamiento del comportamiento sexual de las mujeres, pues clasifica sus prácticas cotidianas como propias de las putas.

Según Lagarde, "el erotismo es el espacio vital reservado a un grupo menor de mujeres ubicadas en el lado negativo del cosmos, en el mal, y son consideradas por su definición esencial erótica como malas mujeres, se trata de las putas" (1997: 182). Si bien el erotismo hace parte de la vida de todas las mujeres, suele estar asociado a la reproducción. Cuando se vive el erotismo como placer femenino, inevitablemente se es puta. Lo anterior se debe a que los esquemas culturales se han constituido con base en tipologías binarias: blanco/negro, masculino/femenino, norte/sur, rico/pobre, entre otras; así, el binarismo femenino en lo referente a la sexualidad sería: casta/puta, buenas mujeres/malas mujeres, ubicando lo primero como lo superior y "lo otro" como lo indeseado.

Desde que una mujer nace, los discursos dominantes sobre el género y la sexualidad instauran modelos que se encargan de configurar "los posibles" de la identidad. "La palabra puta está instalada en nuestras vidas al mismo tiempo que la palabra mamá. Es una palabra biográfica que moldea la identidad, no meramente sexual sino también política: así deberá comportarse, de otra manera se es irremediablemente puta" (Galindo y Sánchez, 2007: 14). Se establece entonces una línea invisible en la vida cotidiana de las mujeres, que hace las veces de frontera y que lleva al enfrentamiento entre ellas y consigo mismas para clasificar sus prácticas como "decentes", propias de una futura madre-esposa sumisa, obediente, pasiva sexualmente, callada y ocupante del espacio privado, o como "putas".

¿Quiénes son las putas hoy? No son únicamente las trabajadoras sexuales, sino que es una etiqueta impuesta a toda mujer que cruce la línea de lo establecido, especialmente en temas concernientes al sexo. Por lo tanto, una mujer es puta si se masturba, si usa métodos anticonceptivos, si aborta, si tiene varias parejas sexuales, si besa a alguien en la primera cita, si no es heterosexual, si tiene hijos de padres diferentes, si se divorcia... El rótulo de puta también se extiende para otro tipo de prácticas no necesariamente sexuales, por ejemplo: invitar a un hombre a bailar, consumir sustancias que alteran la conciencia, emplear lenguaje soez, tener cierto tono de voz, vestirse de cierta manera, resaltar determinadas partes del rostro con maquillaje, tatuarse, perforarse determinadas zonas del cuerpo, tener muchos amigos hombres, salir hasta la madrugada, utilizar cierta gestualidad, ir de fiesta periódicamente, ser exitosa en el 
mundo laboral, tener cierta figura corporal, entre muchas otras. Es decir, escapar del insulto puta termina siendo una labor titánica para las mujeres hoy.

Lo anterior permite pensar, junto con Galindo y Sánchez, que el debate frente a la palabra "puta", que se ha tomado como insulto, pone en juego "el significado político del cuerpo de las mujeres en una sociedad patriarcal" (2007: 67), que cambia de acuerdo con las particularidades contextuales de cada lugar, pues no significa lo mismo ser puta en Colombia o en otro país latinoamericano, que serlo en el medio oriente. Sin embargo, lo que sí es común en las mujeres de cualquier lugar del mundo, es que no pueden ser dueñas de sus propios cuerpos ni de su sexualidad, pues, a los dispositivos jurídicos y religiosos de la Edad Media se les ha sumado el científico (con el médico y el psiquiatra a la vanguardia, seguidos por los científicos sociales) y el mediático que establece un patrón de gobierno sobre la conducta de las mujeres.

Miles de mujeres son subordinadas en el mundo simplemente porque no se ajustan al modelo de "mujer ideal". Algunas veces, son marginadas en sus espacios comunitarios, escolares, laborales o lúdicos; en otras ocasiones, son asesinadas por sus parejas, y algunas de estas muertes se legitiman social y aun jurídicamente por actuar como "putas". Ya no son necesarias las hogueras, basta el nuevo linchamiento social y mediático. Ha sido tan fuerte la implantación de la dicotomía entre las buenas y las malas mujeres, que los inquisidores ya no solo son la iglesia y el estamento jurídico, pues habita un inquisidor en cada uno de nosotros.

\section{Las cacerías de brujas del nuevo milenio}

A continuación, presentamos una serie de cifras de los ámbitos global, continental, nacional y local que muestran que la cacería de brujas no ha desaparecido, sino que se ha transformado a lo largo del tiempo.

Según la Organización Mundial de la Salud, "a nivel global un 35 por ciento de mujeres ha sufrido violencia física y/o sexual en el contexto de relaciones de pareja o violencia sexual fuera de relaciones de pareja" (ONU Mujeres, 2015: 1). Además, de acuerdo con algunos estudios de violencia por países que cita la OMS, hasta un 70 por ciento de mujeres sufre violencia física sexual a lo largo de su vida a manos de su pareja.

Además, muchos casos de violencia que preceden un asesinato no son denunciados, por lo cual no hay registro de ello. Además, según datos publicados en la página web de la Semana por un Mundo Sin Violencias Contra las Mujeres, "la violencia de género mata en el mundo a más mujeres que el cáncer, la malaria, los accidentes de tráfico y las guerras juntas” (2014: 1); cada 15 segundos, en algún lugar del mundo, una mujer es violentada. Además, la principal causa de muerte entre las mujeres de 15 a 44 años en el mundo es la violencia de género.

En América, la violencia física y sexual hacia las mujeres por sus compañeros o ex parejas sentimentales es del $29.8 \%$, superando los niveles de Europa que son del $25.4 \%$ y los países del 
Pacífico Occidental que son de $24.6 \%$, siendo las principales víctimas las mujeres entre 40 y 44 años, según la OMS (2013).

En Latinoamérica, el $25.7 \%$ de las mujeres manifiestan haber sufrido violencia física o sexual alguna vez por su pareja. El 13\% de las mujeres encuestadas expresan que ha sufrido una agresión física o sexual en los últimos doce meses, de acuerdo con el Observatorio de Igualdad de Género de América Latina y el Caribe (2014). Según el informe elaborado por esta entidad, la violencia física y sexual hacia las mujeres está extendida a todos los países y estratos sociales.

La violencia psicológica (maltrato emocional y comportamientos controladores hacia las mujeres) es otro punto álgido en Latinoamérica, pues, de acuerdo con lo presentado en el Informe Anual (Observatorio de Igualdad de Género de América Latina y el Caribe 2014), en países como Nicaragua este tipo de agresiones alcanza el $47.8 \%$ y cifras similares en México y Ecuador.

En Colombia, la situación no es menos dramática. En el Informe "Violencias en Contra de las Mujeres: Situación 2014” (Corporación Sisma Mujer 2015), se expresa que en ese año cada catorce minutos fue agredida una mujer. En este mismo año, el Instituto Nacional de Medicina Legal y Ciencias Forenses realizó 43,807 exámenes médico legales por violencia de pareja en contra de mujeres y hombres. De estos, 37,881 correspondieron a mujeres, es decir el $86,5 \%$ del total, y 5.926 contra varones, es decir el 13,5\%" (Sisma Mujer, 2015: 2), lo que da cuenta de una relación mujer a hombre de $6 / 1$.

En esta misma fuente, se encuentra que, en Colombia, en 2014, cada treinta y tres minutos fue sexualmente agredida una mujer. En este asunto sigue habiendo una relación entre hombres y mujeres de 6/1, entre 16.088 casos denunciados por ellas; esto sin mencionar los casos que no se denuncian por la desconfianza hacia las instituciones. En el informe, que se apoya en cifras del Instituto Nacional de Medicina Legal y Ciencias Forenses -INML y CF- de Colombia, se puede apreciar una categorización de la violencia que señala las particularidades del caso colombiano, puesto que se habla de violencia sociopolítica, es decir, se presentan casos de violencias contra las mujeres como producto del conflicto armado.

En el informe, se precisa que, a raíz de este tipo de violencia, se presentó en 2014 un caso cada dos días por violencia sexual, de los que el 84,73\% de los casos se ejerció contra mujeres, en una relación entre mujeres y hombres de 11/2. Estas cifras superaron las de 2013, cuando estas agresiones se presentaban cada cuatro días en el país; "esto significó un aumento del $93 \%$ de víctimas de 2013 a 2014" (Sisma Mujer, 2015: 5).

Los feminicidios, que son los asesinatos cometidos contra mujeres por el hecho de ser mujeres, alcanzan los índices más altos en Colombia comparada con toda Latinoamérica, con un $88.5 \%$ de víctimas en 2014, lo cual representa una relación mujer a hombre de 8/1. "Esto significó que por lo menos una mujer cada 3 días fue asesinada a manos de su pareja. De 2013 a 2014 se observa un incremento del 29,21\% con víctimas femeninas" (Sisma Mujer, 2015: 7). Hasta el 31 de mayo de 2015, el INML y CF reportó 344 casos de muertes violentas de mujeres en el país. "El informe señala entre el 1 de enero de 2014 y el 31 de mayo de 2015 hubo 167 muertes 
violentas de mujeres menores de edad, lo que corresponde al $12,36 \%$ del total de los casos" (Santiago, 2015: 1).

En Manizales, que es la ciudad en la que escribimos y que hace parte del Departamento de Caldas en Colombia, el fenómeno no es menos preocupante. En el año 2014, 190 mujeres fueron abusadas sexualmente, 234 fueron víctimas de violencia psicológica y 907 fueron violentadas físicamente, según datos de la Secretaría de Salud de la ciudad. Además, el acoso callejero, que es también una forma de violencia que ha sido invisibilizada y socialmente legitimada, ataca a la mayoría de mujeres en los espacios que habitan.

Las cifras citadas indican que las mujeres viven en una sociedad en la que los hombres se ufanan porque "la violé por puta", "la maté por puta", "usted es mía y de nadie más", "por vestirse así les pasa lo que les pasa", "si le pegaron es porque se lo buscó", "seguro lo provocó", "porque te quiero te aporrio". El insulto puta ha servido como arma del patriarcado para justificar la violencia contra las mujeres, incluso su muerte. En Colombia, por ejemplo, hay una expresión que se asocia a lo masculino que es "el putas", y que se define como un hombre valiente, con agallas y de armas tomar, dando paso a que muchos sujetos se autodefinan de ese modo. Con el insulto puta pasa lo contrario, pues las mujeres no se atreverían a denominarse así por las consecuencias sociales que eso acarrea en sus ámbitos familiar, laboral, sentimental o lúdico.

\section{La marcha de las putas en Manizales}

\subsection{Los colectivos de resistencia y disidencia sexual}

En la caracterización y el seguimiento que hace el Colectivo de Investigación "Pluriversos, Cultura y Poder" a la movilización social en Manizales, hemos identificado a Marzo de 2015 la existencia de tres colectivos de disidencia sexual que agencian prácticas colectivas de resistencia ${ }^{2}$ : "Corporación Armario abierto", "Colectiva Subversión Marica" y "Las Guapas".

La Corporación Armario Abierto, nace como una organización social sin ánimo de lucro en 2010, con el objetivo de realizar acciones que defiendan los derechos de las mujeres que ejercen el trabajo sexual en Manizales, pero al año siguiente deciden constituirse legalmente como corporación y ampliar sus intereses hacia las problemáticas de la comunidad LGBTI. Siempre ha estado conformada por jóvenes estudiantes universitarias o profesionales, y hoy es liderada por un grupo de trabajadoras sexuales que, al inicio de la corporación, eran sus sujetos de intervención, pero que se han apersonado de sus luchas y su lenguaje. Su área de trabajo son los

\footnotetext{
${ }^{2}$ Conceptualizadas desde el Colectivo de Investigación Pluriversos, Cultura y Poder como: "desacuerdos públicos frente a múltiples expresiones de injusticia. No son negatividad, por el contrario, son agenciamientos de significados que producen y/o reproducen visiones alternativas del mundo".
} 
Derechos Humanos, siendo el tema de la violencia de género el que ha movilizado a sus miembros desde la creación de la Corporación, y ha creado en la ciudad "La Marcha de las Putas" en el año 2012 y otros espacios de reflexión académica frente al tema como: foros, talleres, cineclub, entre otros.

El grupo de trabajadoras sexuales que hoy lidera la corporación no es nuevo en la ciudad, pues, desde el año 2011, aparecieron en la ciudad con el nombre "Las Guapas". A partir de un proyecto de fortalecimiento comunitario que se desarrolló en su espacio de trabajo y de vivienda, expresión que ha resultado ser un interesante artificio discursivo de resignificación del trabajo sexual en la ciudad, especialmente del ubicado en el sector de la plaza de mercado de la ciudad. Allí, ha sido usual en las últimas décadas ver trabajadoras sexuales en las calles. Este hecho, ligado a las dinámicas propias de la plaza de mercado (ruido, habitantes de calle, acumulación de basuras, consumo de sustancias psicoactivas, visitado especialmente por campesinos y personas de los barrios populares) se convirtió en un imaginario social del lugar como "peligroso", "sucio" y "desordenado".

Una calle del sector, donde habitualmente se ubican las trabajadoras sexuales, era rotulada como "La Calle de la Penicilina", haciendo alusión a un lugar "tugurial" e "infeccioso" habitado por abyectas. En este crisol, surge la expresión "Guapa", ya que, como lo expresan algunas de ellas "estar parado por acá en una esquina, arriesgando la vida, la salud, arriesgando muchas cosas...eso es de Guapas” (Maryuri López, La Patria, 25/11/2013: 1), "Guapas para pararse aquí a las tres de la mañana casi en pelota... hay que ser Guapa" (Maritza Ramírez, La Patria, 25/11/2013: 1). Guapa, alude a alguien bonita, agradable, bien parecida, pero además en Colombia guapo o guapa se asocia con "verraco" y "verraca", un colombianismo que significa persona fuerte, arriesgada, que enfrenta y supera los obstáculos de la vida.

Pues bien, "Las Guapas" de la "galería", en los últimos años (desde que se asumen como tal) han sido objeto de interés de diferentes sectores de la ciudad: artistas académicos les hicieron una escultura, los grafiteros les pintaron su calle llenando de fantasía la anteriormente lúgubre "Calle de la Penicilina" ahora "Calle de las Guapas", organizaciones sociales no han escatimado en esfuerzos por hacer el lobby respectivo con sus proyectos para "intervenir" a las guapas y semestre tras semestre no faltan los trabajos visuales, antropológicos, urbanísticos, psicológicos, médicos y sociológicos de estudiantes universitarios sobre las "famosas Guapas". Ya no son las despreciables prostitutas de la galería, ahora son "Las Guapas".

Ellas han estado vinculadas a la segunda y tercera Marcha de las Putas que, como veremos, no es una marcha de trabajadoras sexuales. Hoy, las Guapas se interesan especialmente por el reconocimiento de derechos para las mujeres transgeneristas que ofrecen servicios sexuales, y son motivadas por los asesinatos que han sufrido dos de ellas en los últimos dos años y que hasta hoy permanecen en la impunidad.

Por su parte, la Colectiva Subversión Marica nace en 2013 y está integrada especialmente por estudiantes de la Universidad de Caldas. Se declara plural, contrasexual, antiheteronormativa y anti-patriarcal, y lucha por la liberación plurisexual mediante la subversión en lo cotidiano; de 
ahí que el performance haya sido una de sus estrategias más utilizadas. Uno de sus propósitos ha sido la concienciación de la población manizaleña sobre las disidencias sexuales, corporales y de género; "Subversión Marica" se vinculó a la Marcha de las Putas, acompañándola en su tercera versión.

Además de Armario Abierto, Las Guapas y Subversión Marica, otros dos colectivos han apoyado el proceso de La Marcha de las Putas, estos han sido el Colectivo Rayuela y el Colectivo de Investigación Pluriversos, Cultura y Poder que, sin ser explícitamente de disidencia sexual, acompañan este tipo de procesos.

El Colectivo Rayuela está conformado desde 2010 por jóvenes que vienen de distintos procesos, específicamente relacionados con el hardcorepunk y cercanos a movimientos anarquistas, feministas y animalistas de la ciudad. Uno de los principales objetivos del colectivo ha sido trabajar alrededor de la contra-información como herramienta crítica de la línea dominante de los medios de comunicación. Desde el año 2013, han venido desarrollando en espacios universitarios el "Oh! Varios Festival", donde buscan hacer visibles las formas alternativas de vivir el género y la sexualidad en la academia, la calle, las contraculturas, el deporte, la música, entre otros espacios. Se vincularon en 2014 al proceso de la Marcha de las Putas, trabajando especialmente en las estrategias comunicativas de la Marcha.

El Colectivo de Investigación-Acción Pluriversos, Cultura y Poder está conformado desde 2013 por estudiantes y profesores de la Universidad de Caldas y busca crear un espacio de reflexión, acción y producción académica frente a las dinámicas y los agenciamientos de los movimientos sociales y colectivos de resistencia de la región, teniendo como referente la relación que se teje entre los procesos culturales y el poder. De ahí que tenga particular interés en acompañar procesos de lucha social, bien sea mediante la divulgación, la solidaridad o el conocimiento académico. Como su actividad se ha guiado por la reflexión sobre cómo "otros mundos son posibles", ha acompañado a los que intentan construir creativamente un mundo incluyente de las diferencias que, con una nueva imaginación social, se posicione a través de la reflexión crítica al sexismo, a la heteronormatividad y a la imposición de imperios monosexuales. Es por esto que desde 2014, decide apoyar La Marcha de las Putas, y en 2015 desarrolló los Putalleres, una estrategia pedagógica de visibilización y denuncia de la violencia de género.

\subsection{Memoria del movimiento}

A raíz de la inevitable estigmatización que viven las mujeres al intentar clasificarlas/se entre decentes y putas, nace en 2011 en Canadá un movimiento que lucha contra la violencia de género, ahora en varios países, y que surge a partir de las declaraciones de un policía en Toronto llamado Michael Sanguinetti, quien aseguró en una conferencia sobre seguridad ciudadana en una universidad, que las mujeres debían evitar salir a la calle vestidas como putas para no ser agredidas sexualmente. Inmediatamente, estas declaraciones surtieron efecto en las mujeres 
canadienses, quienes, bajo el nombre "SlutWalk" (Marcha de las Putas) salieron a marchar para protestar contra la justificación de la violencia hacia las mujeres por su forma de vestir.

Como es sabido, la justificación de la violencia que se ejerce contra los cuerpos de las mujeres no sólo sucede en Canadá, sino en muchos países del mundo, incluidos los Latinoamericanos. Así, inspiradas en la SlutWalk se crea la Marcha de las Putas que, desde ese mismo año, se lleva a cabo anualmente en Colombia, Chile, Nicaragua, Venezuela, Honduras, El Salvador, México, Brasil, Argentina, Costa Rica, Perú, Uruguay, Ecuador, Paraguay, España, India, Australia, Portugal, Reino Unido y Estados Unidos.

El objetivo central de la Marcha, que ha llegado a ser una práctica de resistencia transnacional, es que las mujeres se reapropien del insulto "puta" para combatir todas las formas en que la violencia es ejercida sobre sus cuerpos. La palabra "puta" ha sido utilizada para dividir a las mujeres, para controlar su sexualidad (como en tiempos de la cacería de brujas), para hacerles sentir vergüenza por vivir una sexualidad activa, para juzgarlas por sus acciones desviadas de la feminidad normativa y para legitimar todo tipo de violencia contra ellas (física, psicológica, económica, mediática, política y simbólica). El lema del movimiento en Latinoamérica es: "Puta o no, cuando digo no es NO", como reacción ante la legitimación del acceso carnal violento hacia las mujeres por su forma de vestir.

En Manizales, la Marcha de las Putas nació en febrero de 2012 liderada por la Corporación Armario Abierto, que estaba en ese entonces conformada por jóvenes, en su mayoría mujeres, y que luchaba por la visibilización y el reconocimiento de las situaciones de violencia que vivían las mujeres y los miembros de la comunidad LGBTI.

La tarde del sábado 25 de febrero de 2012, salieron aproximadamente diez personas, en su mayoría mujeres jóvenes y algunos hombres a protestar públicamente por las calles del centro de la ciudad en contra de las violencias contra ellas. Se apropiaron del insulto puta, lo que atrajo la atención de transeúntes y medios de comunicación locales y nacionales. Llevaban carteles y gritaban arengas como: "Me quieres virgen, me quieres santa, me tienes harta", "No quiero tu piropo, quiero tu respeto", "Puta o no, cuando digo NO, es NO". Se realizó un recorrido que llegó hasta la Plaza de Bolívar (plaza central de la ciudad) donde se realizó una "vacunación simbólica" contra el acoso callejero, lo que logró aglomerar gran cantidad de personas a debatir en torno al uso del "piropo".

Algunas personas estaban de acuerdo con la intención de la marcha y otras expresaban públicamente su desacuerdo, especialmente porque no entendían por qué los piropos podrían ser mal recibidos por las mujeres. Para otros, el evento era confuso, porque como se titulaba "de las putas", se imaginaban que quienes marchaban eran trabajadoras sexuales. El gran logro de esta primera manifestación fue reunir a grupos de transeúntes a discutir en torno a la violencia de género. Además, a pesar de que solo fueron un poco más de diez personas las que salieron a marchar, tuvo un importante cubrimiento de medios locales e incluso nacionales, por el morbo que generaba la expresión pública de la palabra puta. 


\section{Imágenes 1 y 2. Primera Marcha de las Putas en Manizales}
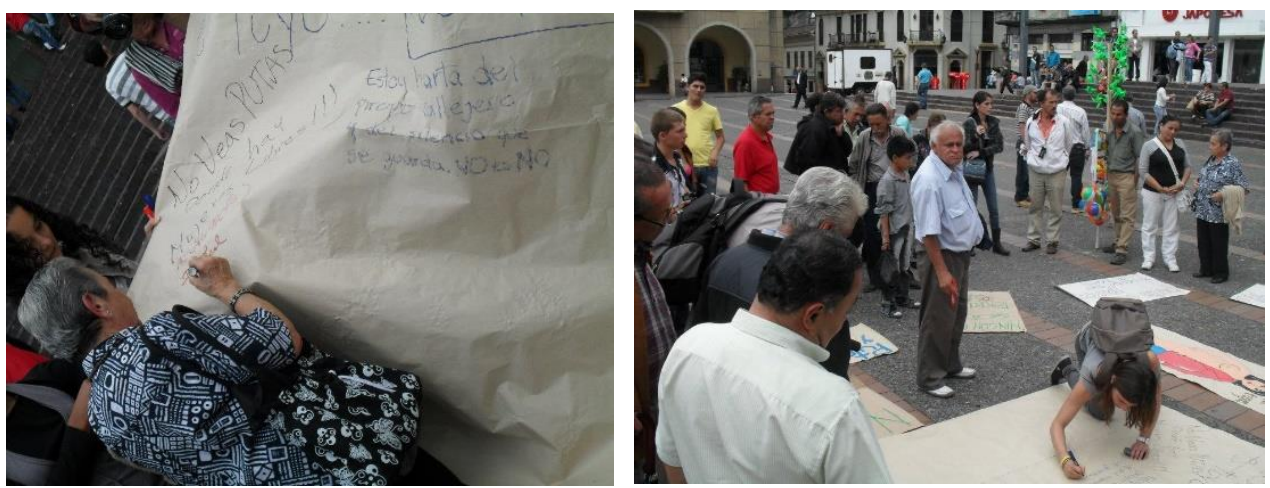

Fuente: Página de Facebook de la Corporación Armario Abierto (2012) ${ }^{3}$

El 6 de abril del año 2013, la Corporación Armario Abierto lideró la segunda manifestación pública de las Putas. Se realizó un plantón en la Torre del Cable, que es un lugar de la "zona rosa" de la ciudad. En esta ocasión, asistieron unas cien personas aproximadamente. Se utilizó la estrategia del mural, en el que bajo el lema "Mi cuerpo no es responsable de tu violencia" los asistentes expresaron por escrito sus opiniones sobre el tema. Este segundo encuentro de la Marcha de las Putas estuvo marcado por el asesinato de Luz Yohana López Vidal, trabajadora sexual y líder de las mujeres trans en Manizales, que fue encontrada sin vida el 31 de marzo de 2013. Ese día se le realizó un homenaje público.

\section{Imagen 3. Segunda Marcha de las Putas en Manizales}

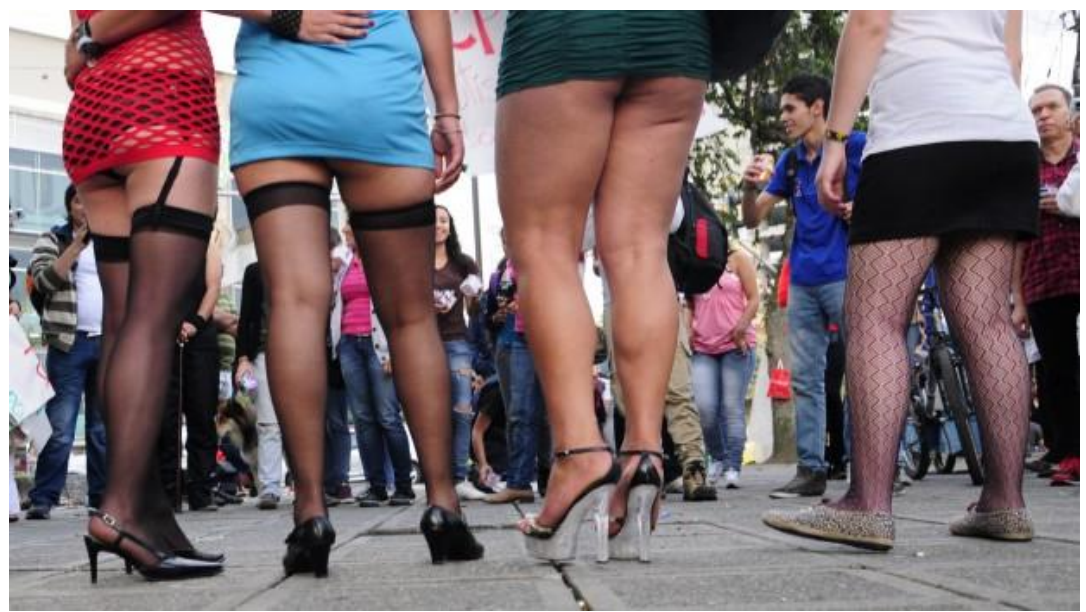

Fuente: Fotografía tomada de Periódico La Patria $(2013)^{4}$

\footnotetext{
${ }^{3}$ Disponible en: https://www.facebook.com/1armarioabierto/?hc_ref=SEARCH [07/01/2017].

${ }^{4}$ Disponible en: http://www.lapatria.com/manizales/marcha-de-las-putas-30493 [07/01/2017].
} 
La tercera versión, realizada el 20 de junio de 2014, la Marcha de las Putas empezó a ser más conocida por la ciudadanía manizaleña, especialmente por jóvenes universitarios, lo que permitió que muchos colectivos se interesaran en adherirse a la planeación y ejecución de la manifestación. Esta vez, se reunieron ocho colectivos:

\section{Imagen 4. Tercera Marcha de las Putas en Manizales}

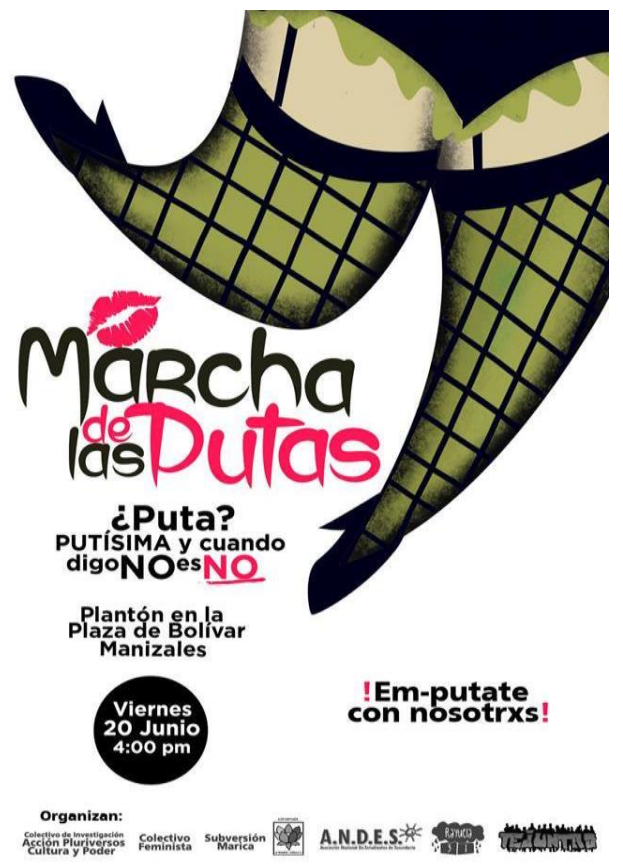

Fuente: Página de Facebook de Pluriversos, Cultura y Poder $(2014)^{5}$

Corporación Armario Abierto, Pluriversos Cultura y Poder, Subversión Marica, Colectivo Rayuela, Las Guapas, Asociación Nacional De Estudiantes de Secundaria (ANDES), Colectivo Feminista y El Lectámbulo.

Los recursos fueron autogestionados en su totalidad por los miembros de los distintos colectivos vinculados, lo que permitió que la Marcha continuara con su tinte de independencia política, sin apoyo de las instituciones estatales.

Se realizó un plantón en la Plaza de Bolívar con actividades como: bodypaint, mural de percepciones “¿Qué putas piensas?”, juegos con el público asistente, diseño y difusión de la pieza comunicativa de la Marcha de las Putas donde se incluyeron estadísticas de violencia contra las mujeres y un manifiesto de la Marcha.

\footnotetext{
5 Afiche de la $3^{\text {a }}$ Marcha de las Putas en Manizales. Disponible en: https://www.facebook.com/1armarioabierto/?hc_ref=SEARCH [07/01/2017].
} 


\section{Imágenes 5 y 6. Tercera Marcha de las Putas en Manizales}
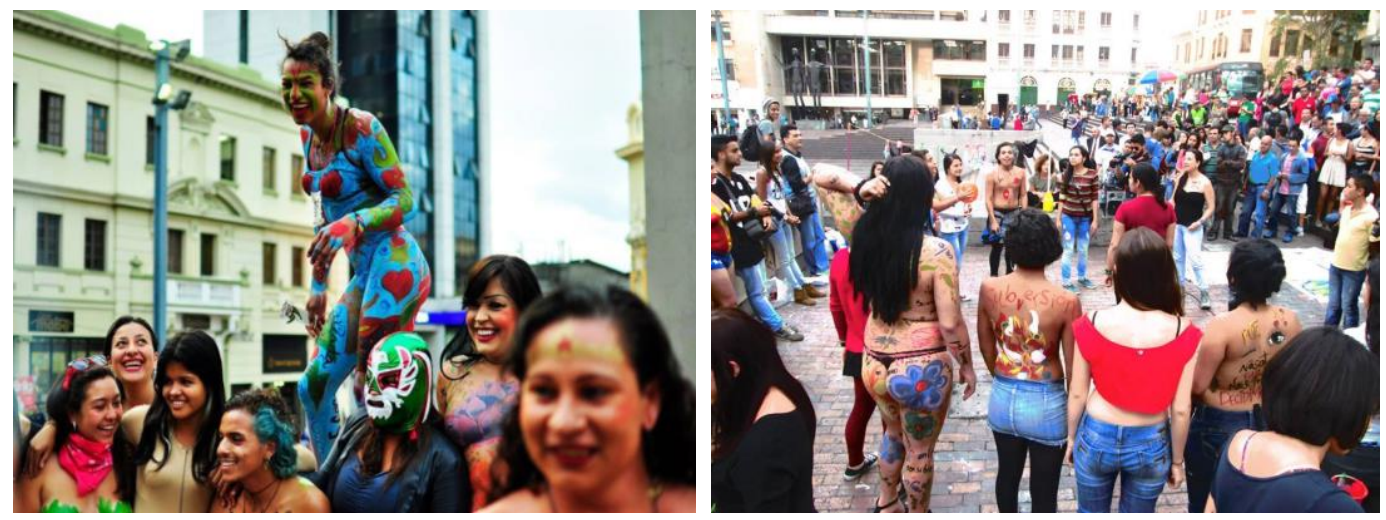

Fuente: Página de Facebook de Subversión Marica $\left(2014^{6}\right)$

También se realizó un altar en memoria de Luz Yohana López (la Guapa asesinada) y carteles que decían frases como: "Saca la Puta del closet”, “¿Si te escandaliza la palabra Puta, por qué no te escandaliza la violencia?”, “Puta? Putísima, y cuando digo NO, es NO”, "Puta porque cuando estabas borracho no te lo di", "Negra, Marica y Puta", "Yo vine porque soy marica y me han dicho que soy puta", "Yo soy la Puta que tiene 3 hijos de papás diferentes" y "Yo soy la Puta que saca a bailar". Al evento asistieron más de mil personas.

Finalizando el año 2014, el Colectivo Pluriversos, Cultura y poder ideó otras posibilidades de intervención con la apropiación del insulto puta, que permitieran un acercamiento pedagógico a las comunidades, pero que no fuera tan fugaz como la marcha o el plantón.

Así, se logró consolidar el proyecto denominado "Putalleres", que se propuso como objetivo crear un espacio de reflexión y sensibilización en torno a la violencia contra las mujeres en las ciudades de Manizales y Villamaría.

El proyecto consistió en diseñar y ejecutar ocho talleres con temas relacionados con la violencia de género: derechos y conceptos básicos, tipos de violencia, acoso sexual callejero, sexismo y estereotipos de género y crítica al amor romántico. Se llevaron a cabo en espacios públicos e institucionales de ambas ciudades, lo que permitió la participación de más de cuatrocientas personas. Se realizó también una acción simbólica por la muerte de la Guapa Luisa Quintero el día 8 de marzo de 2015, cuyo asesinato, junto con el de Yohana López, sigue en la impunidad.

\footnotetext{
${ }^{6}$ Disponible en https://www.facebook.com/groups/225467747613001/ [07/01/2017].
} 


\section{Figura 1. Putaller no 1: "Derechos y conceptos básicos"}

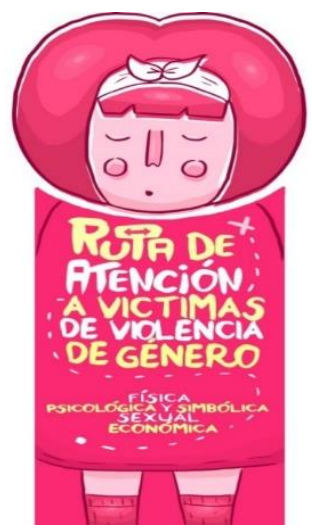

Fuente: Página de Facebook de La ropa sucia NO se lava en casa $(2015)^{7}$

La palabra "puta" nunca será bien recibida en una institución, por lo cual se presentó estratégicamente el proyecto con la campaña "La ropa sucia NO se lava en casa", subvirtiendo una frase que coloquialmente utilizamos en Colombia: "La ropa sucia se lava en casa", y que hace alusión a que los asuntos privados no deben sacarse al espacio público, especialmente cuando son temas de pareja, lo que incluye la violencia. La campaña propició el ingreso a instituciones educativas, aprovechándose este espacio para abordar la reflexión sobre el insulto puta. El colectivo espera que el proyecto "Putalleres" siga desarrollándose liderado por otros colectivos de la ciudad.

\section{Imagen 7. Tercera Marcha de las Putas en Manizales}

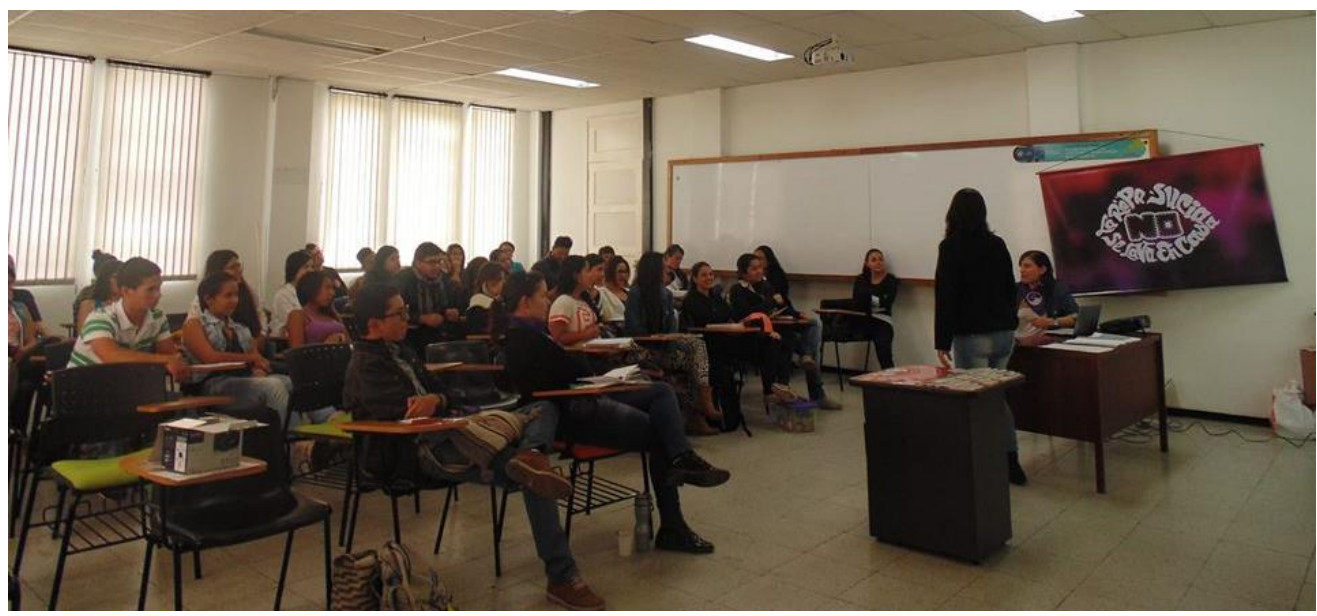

Fuente: Página de Facebook de La ropa sucia NO se lava en casa (2015)

\footnotetext{
7 Separador de libros diseñado para los "Putalleres". Disponible en: https://www.facebook.com/NOselavaencasa/ [07/01/2017]
} 


\section{La puta como locus estratégico de lucha política}

La conocida teoría queer (o cuir o kuir) aparece en el universo académico para producir con su insolencia reflexiones novedosas respecto al género y la sexualidad. Lo queer surge primero en el interior de los procesos sociales de disidencia sexual en Estados Unidos y Europa en los años ochenta, donde algunos colectivos feministas, homosexuales, punks, de activismo frente a políticas de VIH-SIDA, empezaron a usar estratégicamente una palabra utilizada para calificarlos como abyectos y la convirtieron en un objeto de lucha política.

Queer, raro, maricón, bollera, puto, machorra, joto, cacorro, no son identidades sino "locus" de provocación, de transgresión y de develamiento de relaciones de poder sexopolíticas del imperio sexual. Si los queers eran vistos como peligrosos y raros, ellos se apropiarían de esto para volver político aquello que muchos movimientos habían ignorado sobre problemas como la violencia en el ámbito escolar, los crímenes de odio, la homofobia de los medios de comunicación, las políticas estadounidenses de prevención y acompañamiento a pacientes con VIH-SIDA, y las políticas del capitalismo que solo veía en ellos unos sujetos que podían seducir para el consumo de "marcas gay".

Teresa de Lauretis unificaría lo "impresentable": "teoría queer", o en castellano "teoría maricona", "teoría puta", como un modo de hacer visibles en la academia las propuestas de pensamiento y acción de estos colectivos. Desde ese momento, en los años noventa, esta teoría de lo abyecto ha hecho una vertiginosa carrera en universidades y bares del mundo occidental, con Judith Butler como su teórica más reputada y Paul Beatriz Preciado como uno de sus exponentes más mediáticos.

La teoría queer muestra que no solo las invisibilizaciones sino también ciertas formas de visibilización, o mejor de categorización, son ciertamente violentas. Las maneras en que los discursos clasifican ciertas prácticas, cuerpos e identidades y cómo estos son construidos y presentados en el espacio público como peligrosos, feos, indeseables, inmorales, revela las formas en que el poder opera a través de las categorizaciones y en las construcciones de lo normal y lo anormal con sus respectivas performatividades.

La Marcha de las Putas puede ser leída como queer, en la medida en que apropiarse del insulto "puta" resulta útil para llamar la atención sobre el problema de la violencia de género; también sobre la forma en que puede ser analizada la categorización entre las "buenas" y las "malas" mujeres y las maneras en que los discursos han construido ciertos performances como característicos de las unas y de las otras.

Es de resaltar que el movimiento de la Marcha de las Putas no tiene un discurso unificado, pues algunas mujeres utilizan el insulto para realizar una labor pedagógica que extermine el uso 
de esta palabra, pues les resulta indigno ser llamadas de esta manera por cualquier acción. Otras colectividades prefieren reapropiarse del insulto para luchar contra las violencias que se ejercen sobre las mujeres, aunque estas se asuman o no como putas. Este último grupo toma abiertamente las estrategias de lucha del movimiento queer.

"No obstante el nombre, no se trata de una marcha de trabajadoras sexuales sino de todo tipo de mujeres para protestar porque mucha de la violencia sexual se justifica con el pretexto de la apariencia provocadora de las víctimas. Apropiarse del término estigmatizante de "puta" es una actitud desafiante y liberadora. "Puta" se usa no sólo para nombrar a las trabajadoras sexuales; se usa para calificar a las mujeres que no se ajustan a los lineamientos de "decentes"; pero también ciertos hombres utilizan dicho apelativo como venganza cuando una mujer resiste sus avances indeseados. Por eso el calificativo de "puta" les sirve a ciertos hombres como insulto y socialmente se vuelve un arma para mantener a raya a las mujeres: el temor de ser calificadas de "putas" las predispone a aguantar malos tratos o restricciones a sus deseos" (Muriel, 2011: 1).

Las Marchas de las Putas en varias ciudades y países expresan la gran variedad de posturas sobre el tema. Sin embargo, se unifican posturas al exigir que se eliminen todas las formas de violencia (física, psicológica, mediática, económica, simbólica, sexual, etc.) contra las mujeres, y demás seres llamados "putas", en los distintos espacios que se habitan.

En Manizales se pueden identificar dos elementos del uso de la expresión "Puta". Por un lado, apropiarse del insulto permite develar las estructuras de control de la sexualidad, de los cuerpos y las identidades femeninas a través de las categorizaciones que se han hecho sobre las buenas y las malas mujeres. Todo el espectro de discursos construidos sobre lo que debería ser una buena mujer, relega a las mujeres al lugar de la puta.

Así, llamarse estratégicamente puta en una marcha, deja en evidencia dicho patrón de dominación que justifica la violencia de género: son malas mujeres, malas por ser libres. De otro lado, la Marcha de las Putas es una transgresión: “somos putas ¿y qué?”, así como los queers: "soy marica ¿y qué?”, una insolente y creativa manera de ridiculizar el patriarcado y boicotear algunas tecnologías heteronormativas.

La primera requiere un mayor trabajo pedagógico, el objetivo aquí no es que más mujeres se autodenominen putas, sino que comprendan cómo esta expresión y todo lo que ella implica sociológicamente ha sido un comodín del patriarcado, así como lo fue la bruja, para el control sexopolítico de las mujeres. La segunda implica un ejercicio micropolítico, esto es "intoxicaciones" voluntarias, ejercicios de singularización, es decir, la acción libertaria de llamarse puta, asumir que lo personal es político y que se puede desarmar al enemigo apropiándose del denuesto con que se las ha categorizado y estigmatizado. 


\section{A manera de conclusión}

La construcción discursiva de las mujeres como brujas o putas ha sido una de las tantas formas en que históricamente se han oprimido y controlado sexopolíticamente. La Marcha de las Putas en Manizales ha sido una insolente, creativa y experimental práctica colectiva de resistencia que cumple, a partir de la trasgresión, el papel de desentrañar las violencias ejercidas por el patriarcado a través de sus perversas categorizaciones. No obstante, conviene referenciar tres retos de los colectivos que agencian esta iniciativa en la ciudad:

El primero es superar la ambivalencia que algunas veces expresan sus intervenciones públicas, puesto que, para muchas personas, la Marcha de las Putas es un evento de trabajadoras sexuales y, en este sentido, la lucha semiótica que encarnan sus resistencias termina siendo ineficaz si de transformar significados dominantes se trata. Segundo, debe ponerse en objeto de crítica la Puta como identidad, y mejor "deshacer la Puta", esto es, quebrantar las clasificaciones de buenas y malas mujeres; "La Puta" es una identidad estratégica o post-identitaria, es un locus de lucha y resistencia política, un juego de identificación y desidentificación que parodia una política de la identidad.

Y tercero, siguiendo a Wittig cuando afirma que las feministas se han arriesgado a caer en el "mito de la mujer", de la misma manera en que el movimiento obrero ha caído en el mito de la clase, no hay que olvidar que la disputa contra el patriarcado y el régimen heteronormativoheterrorista, ocurre respecto a las multitudes sexuales y no solo respecto a las mujeres, y aunque, reconociendo que son ellas quienes han sido por excelencia objeto de la dominación y de control sexopolítico, una verdadera lucha contrahegemónica de liberación del imperio sexual requiere de "las putas" y de la articulación de las voluntades colectivas que estén prestas a sumarse a la contienda. 


\section{BIBLIOGRAFÍA}

- Ángel, Darío (n.d.): “Las brujas”. En: Revista de estudios de filosofía. Artículo en fase de publicación.

- Blazquez Graf, Norma (2008): El retorno de las brujas. Incorporación, aportaciones y críticas de las mujeres a la ciencia. México D.F.: Universidad Nacional Autónoma de México.

- Corporación Sisma Mujer (2015): Violencias en Contra de las Mujeres: Situación 2014. Bogotá, D.C.: Área de Investigación.

- Covarrubias, Sebastián (1611): Tesoro de la Lengua Castellana o Española. Madrid: Luis Sánchez.

- De Sousa Santos, Boaventura (2005): Renovar la teoría crítica y reinventar la emancipación social. Buenos aires: CLACSO.

- Federici, Silvia (2010): Calibán y la bruja. Mujeres, cuerpo y acumulación originaria. Madrid: Traficantes de Sueños.

- Galindo, María y Sánchez, Sonia (2007): Ninguna mujer nace para puta. Buenos Aires: Ediciones Lavaca.

- Lagarde, Marcela (1997): La sexualidad. México, D.F.: UNAM.

- Observatorio de Igualdad de Género de América Latina y el Caribe (2014): Informe anual 2013-2014: El enfrentamiento de la violencia contra las mujeres en América Latina y el Caribe. Santiago de Chile: CEPAL.

- ONU Mujeres (2015): "Hechos y cifras: Acabar con la violencia contra mujeres y niñas". En: Poner fin a la violencia contra las mujeres. Disponible en: http://www.unwomen.org/es/whatwe-do/ending-violence-against-women/facts-and-figures [07/01/2017].

- Organización Mundial de la Salud (2013): Global and regional estimates of violence against women: prevalence and health effects of intimate partner violence and nonpartner sexual violence. Ginebra: Department of Reproductive Health and Research.

- Salinas, Muriel (2011): "La marcha de las putas". En: La Jornada. Disponible en: http://www.lajornadaguerrero.com.mx/2011/07/18/index.php?section=opinion\&article=002a $1 \mathrm{~s}$ oc [07/01/2017].

- Semana por un Mundo Sin Violencias Contra las Mujeres (2014): “Tu Voz Cuenta: Semana por un mundo sin violencias contra las mujeres". En: AECID. Disponible en: www.aecid.es/galerias/descargas/noticias/Datos_Violencias.doc [07/01/2017].

- Valenzuela, Santiago (2015): "Entre 2014 y 2015 van 1.351 feminicidios: Medicina Legal”. En: El Colombiano. Disponible en: http://www.elcolombiano.com/colombia/entre-2014-y-2015van-1-351-feminicidios-medicina-legal-1-IC2352039 [07/01/2017].

- Volpe, Gioacchino (1971): Movimenti Religiosi e Sette Radicali Nella Societá Medievale Italiana, Secoli XI-XIV. Florencia: Sansoni. 